\title{
Irritable bowel syndrome
}

\section{By J. O. Hunter, Addenbrooke's Hospital, Hills Road, Cambridge CB2 $2 Q Q$}

The irritable bowel syndrome (IBS) is not a homogeneous entity but comprises a group of poorly defined conditions all of which produce abdominal pain associated with variability of bowel habit. No universal therapy can therefore exist for IBS, but in recent years we have studied one broad subgroup in which gastrointestinal upsets are produced as a result of food intolerance.

The frequency of food intolerance in East Anglia is approximately two-thirds of patients with IBS (Alun Jones et al. 1982; Hunter et al. 1984). Bentley et al. $(1983)$ in Manchester, found a lower incidence with only three of their twentyseven patients having objective evidence of food intolerance. However, we consider their dietary technique to have been sub-optimal, leading to an underestimate of the true prevalence.

Dietary studies to identify these patients must be meticulously pursued. Initially we used a very strict diet comprising one meat, one fruit, rice and water but we have since been able to streamline the dietary regimen by excluding only those foods which experience has shown affect more than $20 \%$ of our patients. Full

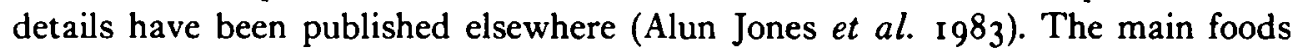
involved are cereals, dairy products, coffee, tea, chocolate, potatoes, onions, citrus fruits and chemical food additives.

Food-related IBS occurs predominantly in women and its onset often follows abdominal or pelvic surgery, bouts of gastroenteritis or repeated courses of antibiotics. The relative importance of surgery and antibiotics was studied in Cambridge in patients undergoing hysterectomy. Women ( $n$ II 3$)$ who had no gastrointestinal symptoms pre-operatively, were under the care of six gynaecologists, four of whom routinely gave metronidazole at the time of surgery and two who did not. All the patients were followed up by postal questionnaire 6 weeks after the operation and thirteen indicated that they had developed symptoms of IBS. Twelve of them were in the group of seventy-four who had received metronidazole.

The association with antibiotics suggested that changes in the bacterial flora of the colon were important in the pathogenesis, particularly in the light of metronidazole's known effects on anaerobic and aerobic bacteria (Lewis et al. 1977). With the collaboration of the Food Research Institute at Norwich, we have completed a pilot study of the response of gut bacteria to food challenge. Higher numbers of aerobes were found in faecal samples from patients than those from age- and sex-matched controls and in two patients a 100-fold increase in the number of aerobes occurred during challenge. 
Table 1. Excretion of aerobic bacteria in faeces (Bayliss et al. 1984)

(Viable bacteria g dry weight)

$\begin{array}{lcccc} & n & \text { Samples } & \text { Mean } & \text { Range } \\ \text { Patients } & 6 & 30 & 2.2 \times 10^{9} & 2.9 \times 10^{7}-1.1 \times 10^{10} \\ \text { Controls } & 6 & 6 & 9.8 \times 10^{7} & 3.9 \times 10^{6}-2.7 \times 10^{8}\end{array}$

There were noticeable changes in the predominant aerobic flora of four patients and anerobic flora of three patients as judged by colony morphology and microscopy. Much lower numbers of bifidobacteria were isolated than expected (Croucher et al. 1983).

In view of the considerable current interest in the concept of 'food allergy' we have sought evidence of immunological abnormalities in these patients but have found little (Alun Jones et al. I982). Only II $\%$ had a history of atopy (Hunter et al. 1984), and this was unrelated to the release of histamine from the jejunal mucosa on incubation with gliadin which we have observed in wheat-intolerant patients, and those with Coeliac disease (McLaughlan et al. 1983), and which we therefore suspect to be a pseudo-allergic response (Stanworth, 1980).

Studies of gut hormone release after food challenge have not revealed any abnormality (Hunter \& Alun Jones, 1984). However, it is becoming apparent that there may be several mechanisms for the production of food intolerance in patients with gut symptoms and further studies to delineate these will help in both diagnosis and management.

Although the detection of food intolerances is difficult, if it is successful it is well worthwhile. Of 122 patients followed up by postal questionnaire 2-20 months after discharge from the clinic, I 2 replied and all were still well on their diets. Sixty-one replied out of seventy-one who were followed up 22-39 months after discharge and of them fifty-six remained well (Hunter et al. 1984).

As the general prognosis of IBS is good, many clinicians do not believe that the considerable effort required to separate the various causes is justified. IBS, however, has a considerable morbidity in terms of chronic invalidism and time off work, and if the medical profession is to maintain the trust of the general public and reverse the growing interest in 'alternative medicine' (Anon., 1983) it will be necessary for gastroenterologists to work out cases of IBS with the same meticulous care that they now give to more serious conditions.

\section{REFERENCES}

Alun Jones, V. \& Hunter, J. O. (1983). In Doctor, There's Something Wrong With My Guts, pp. 183-192 [R. E. Pounder, editor]. Welwyn Garden City: Smith Kline and French Laboratories Ltd.

Alun Jones, V., Shorthouse, M., McLaughlan, P., Workman, E. \& Hunter, J. O. (1982). Lancet ii, III -1117 .

Anon. (editorial) (1983). Physician heal thyself. The Times 12 August, p. 9.

Bayliss, C. E., Houston, A. P., Alun Jones, V., Hishon, S. \& Hunter, J. O. (I984). Proceedings of the Nutrition Society 43, 16A. 
Bentley, S. J., Pearson, D. J. \& Rix, K. J. B. (I983). Lancet ii, 295-297.

Croucher, S. C., Houston, A. P., Bayliss, C. E. \& Turner, R. J. (1983). Applied Environmental Microbiology 45, $1025^{-1033}$.

Hunter, J. O. \& Alun Jones, V. (1984). In The Irritable Bowel Syndrome [N. W. Read, editor]. London and New York: Academic Press (In the press).

Hunter, J. O., Workman, E. \& Alun Jones, V. (1984). In Topics in Gastroenterology, vol. 12, [P. R. Gibson and D. P. Jewell, editors]. London: Blackwell Scientific (In the Press).

Lewis, R. P., Widerman, P., Sutter, V. L. \& Finegold, S. M. (1977). In Metronidazole, pp. 307-319 [S. M. Finegold, editor]. Amsterdam: Excerpta Medica.

McLaughlan, P., Hunter, J. O., Easter, G.B., Alun Jones, V., Calladine, M. R. H. \& Coombs, R. R. A. (1983). In Second Fisons Food Allergy Workshop, pp. 7-9, [R. R. A. Coombs, editor]. Oxford: Medicine Publishing Foundation.

Stanworth, D. R. (1980). Pseudo-Anaphylactoid Reaction, pp. 56-107. Basel: Karger. 